\title{
The day we made history
}

Don't look back....

I should have known better than to draw Wesley's attention to the advertisement in Spiritual Physics. Our chairman had no intention of spending his life running the Mixatap Centre for Quantum Appliances at the University of Central Sidmouth. Seizing his opportunity, he cornered us at the coffee machine.

"Have you seen Godwit and Pond's paper on strong decoherence?" he said, waving a copy of Qubit.

"I have," said Sandra. "But putting their ideas into practice would take a massive amount of equipment, and we don't have the funding."

"Not yet," said Wesley, opening Spiritual Physics at a double-page advertisement and holding it to his chest for us to read.

"The Trumpington Foundation?" squeaked Pete.

"Call for proposals," Wesley said. "Historical Reconstruction Project."

"Oh, come on, Wesley. They're not interested in genuine history. What they want is so-called 'scientific proof' of biblical events."

"Agreed. But they're offering a grant of $\$ 30$ million."

"How do you propose to divert funding for historical evidence of supernatural events into quantum computation?" I asked.

"I thought that instead of digging up the past, we could simulate it."

"You want to compute the Crucifixion?"

"Of course not." I relaxed. "We need to think bigger." I tensed. "I don’t believe you can cherry-pick historical incidents. History is a single system."

"Oh no," I groaned. "Wes, it's been done. Isaac Asimov. Psychohistory. The great Hari Seldon forecast the entire history of the Galactic Empire as it plunged into anarchy. But that was fiction, and even Asimov had to write some extra books to patch the holes. Chaos, for starters."

"Godwit and Pond explain in rigorous detail why chaotic effects do not, in fact, change the course of history."

"Yeah," Sandra chipped in. "It's not a matter of one stupid butterfly flapping its wing and causing a tornado. There's zillions of butterflies, flapping like crazy all the time.
What one flap creates, the next destroys. It all averages out."

"Yes, and it averages out to one thing. Quantum simulations of history always give a unique result, provided they're really big simulations."

"So...we get hundreds of quantum computers, and simulate the whole of human history, right?"

"Wrong. We spend this grant on a feasibility study, and simulate the twentieth century. When that works, we hit Trumpington for a really big grant."

"But Wes, where would the simulation start?" I asked. “There's no way to get accurate initial conditions." Wesley's face fell. "Hadn't thought of that."

But Pete's eyes were shining. "Not a problem. We start from the present and work backwards."

To cut a long story short, we got the grant. We bought 10,000 QQorp MR2s, with Extel ParacoreMulto QPUs. We hooked the lot into the Gnet, and imported every present-day fact available. Then we ran Schrödinger's equation in reverse time, to work out what history had been.

The feasibility study checked out in every detail, right down to who really assassinated Kennedy. Trumpington was impressed; we bought another half a million MR2s, and calculated our way back towards the Middle Ages.

The Domesday Book reconstruction was word-perfect, and we celebrated. But somewhere around 990 the simulation went off the rails.

It was Pete who spotted it. "Hang on... shouldn't Vladimir of Kiev be a Christian by now?"

Sandra pulled up a data-window. "He should have converted in $988 . "$

"So why is he building a Temple of Mithras?"

"What?"

"Maybe he converted back," I said, but somehow I doubted that. "Let's call Wesley."

But when Wesley arrived, none of us could work out why we'd called him. The simulation was spot on. Vladimir's temple bore a striking resemblance to the famous building in Kiev that currently attracted pilgrims from all over Europe. With Wesley as our Heliodromus, we chanted a Yasht in praise of Mithras, to celebrate the accuracy of our simulation.

But later that evening, we once more became concerned. The Aztec invasion of Australia didn't seem to be following the expected pattern, and the Chinese Empire was totally out of whack, except along the Icelandic coast. Sandra ran a few tests, and called a Holy Conclave.

"Fellow initiates," she said. "I have bad news. I have looked up some obscure files, and we are in the wrong universe."

"Don't be stupid, Sandra."

"To be precise, we are in a superposition of our original universe with the simulated one. Practical quantum computation requires entanglement on the level of bulk matter. Unfortunately, our simulation was so massive that it became entangled with the real world."

"You mean...?"

"The world has in effect become our simulation - which turns out to be hopelessly inaccurate. Or would be, except that the world is changing to match it. Aside from a few vestiges of the original, such as the anomalous files I just showed you. Which are slowly fading, even as I speak."

We all thought about this. Eventually I broke the silence.

"Which anomalous files, Sandra?"

"Files? I didn't mention any files!"

"Then why did you invoke this conclave?"

"To report that the simulation has now reached regnal year 12 of Queen Nefershepsut of Jerusalem, and it remains perfect in every detail."

"Praise be to Napoleon of Lancaster!" we cried in unison. I looked out of the window. Herds of camelopard grazed the nearby plains, and huge galleys laden with electrum from the mines of Atlantis were moored in the harbour. A procession of domesticated mammoths made its way through the city, as the Lemurian virgins gave thanks for the Rebirth of the Sun in a ceremony as old as time itself.

I sighed.

All was exactly as it should be.

Ian Stewart

Ian Stewart is co-author of Wheelers, Heaven and the Science of Discworld trilogy. When not writing books, he also manages to squeeze in some serious mathematics at the University of Warwick. 